\title{
Ellipsometry examination of copper alloys with transitive metals
}

\author{
Y.V. Filipov, V.S. Staschuk, L.V. Poperenko, V.V. Vovchenko \\ Department of Physics, Kyiv National Taras Shevchenko University, 6, prospect Glushkova, 03127 Kyiv, Ukraine \\ E-mail: filipov@univ.kiev.ua
}

\begin{abstract}
Electron structure of copper alloys with 3d transition metals (Fe, Co and $\mathrm{Cr}$ ) have been studied basing on elliposometrical measurement of $\Delta$ and $\Psi$ in wide spectral range $h v=$ $1.0-4.95 \mathrm{eV}$. Spectral dependences of $\mathrm{Cu}-\mathrm{Cr}$ alloys optical conductivity in wide range of chrome concentration $(\mathrm{C}=2.5-30$ at. \%) have been minutely analyzed in this work. Ascertainment that in spectrums of studied alloys (and for copper alloys with other transitive metals) were observed basic band of pure $\mathrm{Cu}$, in addition supplementary band in range 1-2 eV were observed too. Is shown that at small $\mathrm{Cr}$ concentrations $(C<5$ at. $\%)$ alloy is forming a single band similar to copper, with insignificant dependence of Fermi level EF from impurity concentrations. Besides there was founded that in electron structure appear impurity bands situated between Fermi level and $d$-band of copper. They split on $0.4 \mathrm{eV}$ as a result of spin-orbit interaction. At high impurity concentrations $\left(C_{\mathrm{Cr}}>5\right.$ at. \%) the alloys are heterogeneous mixtures of pure transitive metals and copper based solid solution.
\end{abstract}

Keywords: Spectroellipsometry, refractive index, absorption index, optical conductivity, copper, alloy, transitive metals, energy structure, density of electron states, impurity bands.

Paper received 14.04.04; revised version 07.09.04; accepted for publication 21.10.04.

\section{Introduction}

Among all $3 d$ transition metals, only $\mathrm{Ni}$ is well soluble in copper under formation of continuous series of solid solutions with fee lattice [1]. Other transition metals, e.g., $\mathrm{Fe}$, are low soluble, while Co and $\mathrm{Cr}$, according to literature, are almost copper-insoluble [1]. In this case, optical characteristics, such as refraction $n$ and absorption æ indices, the dielectric permeability $\varepsilon$ and optical conductivity $\sigma$ must be described by linear functions of impurity concentration. This is due to that, according to [1, 2], the alloys are heterogeneous mixtures of almost pure copper and impurity, thus, the experimental spectra of the mentioned quantities must be formed by superposition of spectra of the mentioned components with the corresponding weight coefficients.

In this work, the optical properties of binary copper alloys with low content of $\mathrm{Fe}$, Co and $\mathrm{Cr}$ have been studied within the spectral range where the interband electron transitions play the main part. The results obtained evidence that the limiting solubility of $\mathrm{Fe}, \mathrm{Co}$ and $\mathrm{Cr}$ in copper is substantially higher than it was believed before.

In the case of $\mathrm{Cu}$-Ni solid solutions, a narrow $d$-band in electron spectrum has been revealed which is associated with $\mathrm{Ni}$ and is situated between the top of $d$-band and the Fermi level [2, 3]. Since other transition metals, espe- cially $\mathrm{Co}$, are closely similar to $\mathrm{Ni}$ in their physical properties, the formation of the impurity band in alloys is to be expected if those are single-phase. Before, a comprehensive research of impurity bands by optical method was carried out for a series of $3 d$ transition metal alloys. In parallel, the electronic structure of disordered alloys was studied rather intensely using theoretic methods promoted by optical researches of the precious metal alloys [4, 5].

Studying the absorption spectra of $\mathrm{Cu}-\mathrm{Fe}$ and $\mathrm{Cu}-\mathrm{Cr}$, it was determined that small impurities of $\mathrm{Fe}, \mathrm{Cr}$ and $\mathrm{Ni}$ do not influence essentially the position of $s p$ - and $d$-bands connected genetically with $\mathrm{Cu}$. Changes in electron spectra of all the alloys, like the $\mathrm{Cu}-\mathrm{Ni}$ ones, occur mainly between the top of $\mathrm{Cu} d$-bands and the Fermi level $E_{F}$ due to formation of the impurity band (with position depending on impurity type), in spite of different solubility of the mentioned metals in copper. Optical methods allow getting a series of parameters characterizing the impurity band, for example, its half-width $\Delta$, its center position with respect to the Fermi level $E_{d}-E_{F}$, and a series of other electron parameters can be calculated proceeding from the above ones.

\section{Experimental details}

The optical properties of $\mathrm{Cu}-\mathrm{Fe}, \mathrm{Cu}-\mathrm{Co}$ and $\mathrm{Cu}-\mathrm{Cr}$ alloys have been studied basing on the constants $n$ and $æ$ meas- 


\section{Y.V. Filipov et al.: Ellipsometry examination of copper alloys with transitive metals ...}

ured at ambient temperature within the wavelength range $\lambda=0.25-1.24 \mu \mathrm{m}$ (or photon energy range $h v=1.0$ $4.95 \mathrm{eV}$ ) by ellipsometric method. The samples of alloys with impurity content from 2.5 to 40 at. \% are prepared by vacuum arc melting in argon atmosphere using several consecutive melting's. The samples were annealed for 24 hours in the same atmosphere at $900^{\circ} \mathrm{C}$ to provide the most possible homogeneity. The mirror surfaces of samples were prepared by mechanical grinding and polishing by diamond powders and pastes of different abrasive grain sizes. The recrystalisations anneal in vacuum at $450^{\circ} \mathrm{C}$ during 3 hours and electric polishing was carried out to remove surface strains.

\section{Experimental results and discussion}

The curves of the optical conductivity dispersion $\sigma(h v)$ are of the most interest in studying optical properties of the alloys. Using these curves, the data can be obtained on the changes in electron spectrum of copper doped with $3 \mathrm{~d}$ transition metals, because $\sigma$ is connected directly with interband density of electron states [6]. The experimental curves $\sigma(h v)$ for $\mathrm{Cu}-\mathrm{Fe}, \mathrm{Cu}-\mathrm{Co}$ and $\mathrm{Cu}-\mathrm{Cr}$ alloys are shown in Figs 1-3, respectively. In these Figures, the curves for pure components are presented, too.

It is seen that within the photon energy region $h v<$ $<1.5 \mathrm{eV}$ the optical conductivity $\sigma$ of copper monotonously increases as $h v$ decreases. This means that it is just free electrons that contribute mainly to absorption due to transitions within each band crossing the Fermi level. In $\mathrm{Cu}-\mathrm{Co}$ alloys, as well as in $\mathrm{Cu}-\mathrm{Cr}$ ones, the contribution of free carriers are almost unobservable within spectral range under study. From our own data that the characteristic peculiarities of the copper optical spectrum are sharp edge of the interband absorption at the photon energy $h v=2.1-2.3 \mathrm{eV}$ as well as very intense absorption band with a maximum at photon energy about $4.62 \mathrm{eV}$. These peculiarities of the copper optical spectrum are

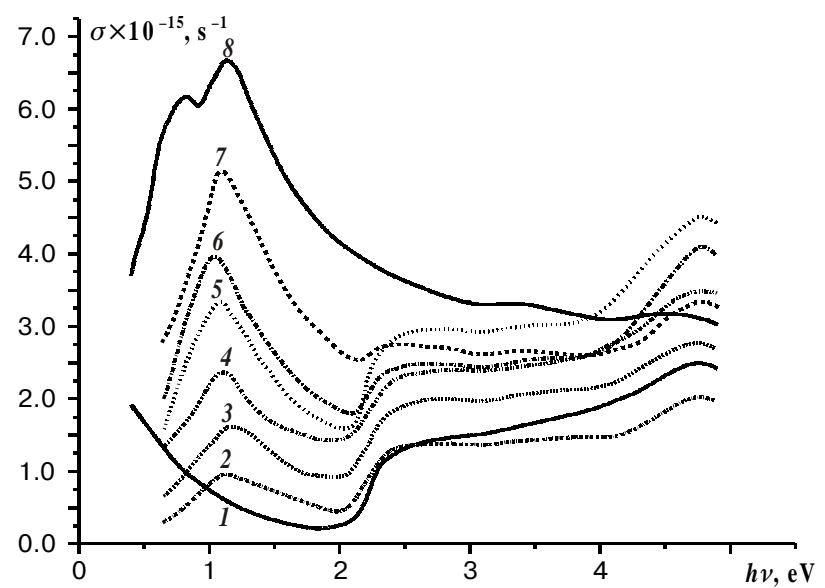

Fig. 2. Optical conductivity dispersion of $\mathrm{Cu}-\mathrm{Co}$ alloys with $\mathrm{Co}$ content (at. \%): 2.5 (2), 5 (3), 10 (4), 17.5 (5), 30 (6) and 50 (7) as well as for pure $\mathrm{Cu}(1)$ and $\mathrm{Co}(8)$. Curves 3 and 7 are lifted up by $5 \cdot 10^{3} \mathrm{~s}^{-1}$ and $4-6$, by $10^{4} \mathrm{~s}^{-1}$.

manifested, to a higher or lower extent, for all alloy samples. The experimental data allow evaluating the threshold of the optical interband absorption as the half-sum of the energy values corresponding to maximum and minimum $\sigma$ near the absorption edge. This value is equal to $2.2 \mathrm{eV}$ for pure copper but in alloys it is within limits of 2.21-2.24 eV, i.e. remains essentially unchanged upon $\mathrm{Co}$ and $\mathrm{Cr}$ addition to the alloy. In all alloys studied, there is also the main band with a maximum at $4.58-4.65 \mathrm{eV}$, i.e. the band is shifted along the energy scale by $0.3-0.4$ $\mathrm{eV}$ only with respect to the maximum for copper. Except for these two features, a weak maximum is revealed for alloys at photon energy $3.5-3.6 \mathrm{eV}$ that is more pronounced for alloys with high $\mathrm{Cr}$ content. We cannot find experimentally that maximum for the pure copper although it is very pronounced in the theoretical $\sigma(h v)$ curve constructed using the calculated electron spectrum data for this metal.

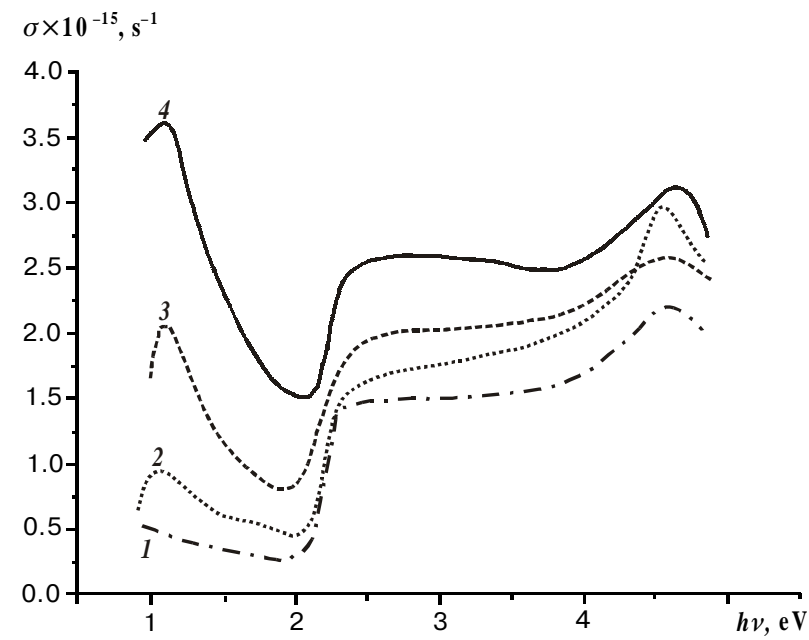

Fig. 1. Optical conductivity of pure $\mathrm{Cu}(1)$ and for $\mathrm{Cu}-\mathrm{Fe}$ alloys with Fe content (at. \%): 7.5 (2), 15 (3) and 30 (4).

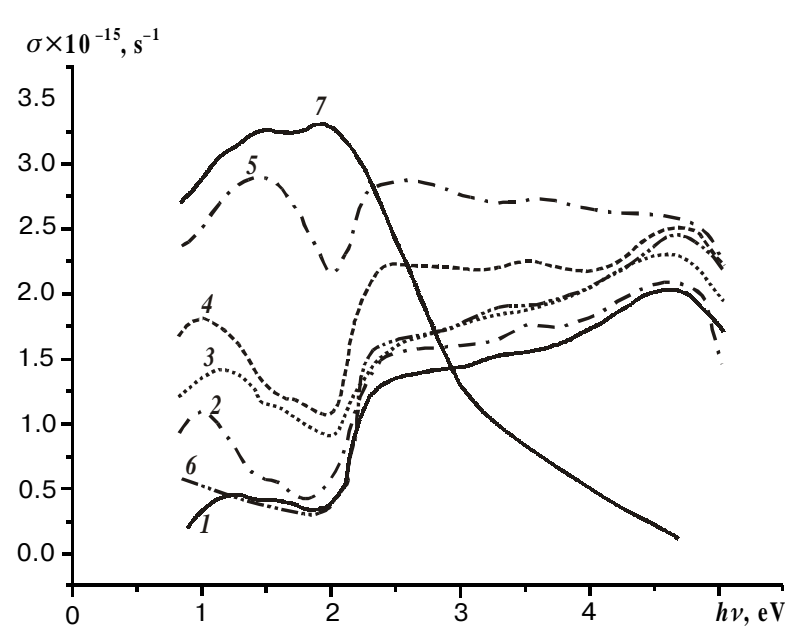

Fig. 3. Optical conductivity of $\mathrm{Cu}-\mathrm{Cr}$ alloys with $\mathrm{Co}$ content (at. \%): $2.5(1), 5(2), 10(3), 17.5$ (4) and 30 (5) as well as for pure $\mathrm{Cu}(6)$ and $\mathrm{Cr}$ (7). Curve 4 is lifted up by $0.3 \cdot 10^{3} \mathrm{~s}^{-1}$ and 7 by $3.6 \cdot 10^{4} \mathrm{~s}^{-1}$. 


\section{Y.V. Filipov et al.: Ellipsometry examination of copper alloys with transitive metals ...}

Alloying of $\mathrm{Cu}$ with $\mathrm{Co}$ and $\mathrm{Cu}$ with $\mathrm{Cr}$ is found to cause a strong effect, namely, appearance of a very intense band in $\sigma(h v)$ curves in the near IR region of the absorption spectrum at the photon energy hv from 0.8 to $1.8 \mathrm{eV}$. Its intensity increases monotonously with increasing impurity content. For $\mathrm{Cu}-\mathrm{Cr}$ alloys, this band has composite structure and consists of a several components. For the alloys containing 2.5 at. \% $\mathrm{Cr}$, these maximums correspond to the photon energy 1.34 and $1.70 \mathrm{eV}$ (Fig. 3). At $\mathrm{Cr}$ concentration 5 at. \%, the long-wave band intensity increases sharply but its maximum becomes shifted towards lower energy values by about $0.26 \mathrm{eV}$. At a further increasing of $\mathrm{Cr}$ concentration, the long-wave band intensity increases but not so sharply. The maximum of this band for alloys with $\mathrm{Cr}$ content 10 and 17.5 at. \% is at photon energy 1.10 and $1.24 \mathrm{eV}$, respectively. In the alloy with $30 \% \mathrm{Cr}$, only one absorption band with a maximum at $1.50 \mathrm{eV}$ is observed. It should be noted that there are no peculiarities in the energy range $1.10-1.34 \mathrm{eV}$ where the maximum of the long-wave band is situated in $\sigma(h v)$ spectra of pure $\mathrm{Cu}, \mathrm{Co}$, and $\mathrm{Cr}$. For copper, a slight increase in $\mathrm{o}$ as the photon energy decreases is characteristic in the mentioned range, which is connected with free carrier absorption. In addition, the fact is worth to note that for the alloys, the intensity of high-energy maximum at $4.65-4.75 \mathrm{eV}$ associated with $\mathrm{Cu}$ depends very weakly on the impurity concentration. The mentioned facts evidence that the $\sigma(h v)$ spectra of the alloys cannot be obtained by simple superposition of $\mathrm{Cu}$ and $\mathrm{Cr}$ as well as of $\mathrm{Cu}$ and $\mathrm{Cr}$ ones with corresponding weight coefficients, as could be expected according the data of the well-known reference book [1] where the solubility of $\mathrm{Co}$ and $\mathrm{Cr}$ in copper is said to be not more than 0.8 at. \%.

In other words, in accordance with [1], e.g., $\mathrm{Cu}-\mathrm{Cr}$ alloys comprise two phases: almost pure $\mathrm{Cr}$ and $\mathrm{Cu}-\mathrm{Cr}$ solid solution (the concentration $N_{\mathrm{Cr}}<0.04-0.8$ at. \%). The results of the computer simulation have shown that the optical conductivity spectra of alloys cannot be obtained by simple summation of those for pure $\mathrm{Cu}$ and $\mathrm{Cr}$ with weight coefficients determined by the lever rule [1]. Moreover, the experimental spectra cannot be get also under suggestion that the alloy components are pure $\mathrm{Cr}$ and solid solution $\mathrm{Cu}-\mathrm{Cr}$ at $\mathrm{Cr}$ concentration of 2 at. \%. The experimental spectrum agrees well with the calculated one in the case when $\mathrm{Cr}$ solubility in $\mathrm{Cu}$ is suggested to be not less than 5 at. $\%$ and increases further as the $\mathrm{Cr}$ concentration rises. Almost the same situation takes place in $\mathrm{Cu}-\mathrm{Co}$ alloys.

Here after, let $\mathrm{Cu}-\mathrm{Cr}$ alloys be considered in more detail. Taking into account the results of electron structure research of pure copper and it optical spectrum, a model of electron structure for the $\mathrm{Cu}-\mathrm{Cr}$ solid solution can be proposed basing on the data obtained. In accordance with [7], the absorption edge for pure copper at photon energy $2.1-2.2 \mathrm{eV}$ is associated with the electron transition from the top of d-bands near the $L_{3}$ point of the Brillouin band to unoccupied states of $L_{2}^{\prime}$ type $s p$-bands in the vicinity of the Fermi level EF. The energy band structure of copper is shown in Fig. 4 where the possible transitions forming the optical conductivity spectrum $\sigma(h v)$ are shown by the arrows. From the experimental data on the optical properties of $\mathrm{Cu}-\mathrm{Cr}$ alloys and the interpretation of the absorption edge, a conclusion can be drawn that for the $\mathrm{Cu}-\mathrm{Cr}$ solid solution, not only the distance between the $d$-band top and the Fermi level remains unchanged but the whole structure of bands shifted from Fermi level by $2.2-2.3 \mathrm{eV}$ does not change.

The intense absorption above the absorption edge is connected with electron transitions in a large volume of the Brillouin band [8] in directions $L-W$ and $X-F$ (the possible transition are shown on Fig.4 by arrows). The optical spectrum (hv) in the photon energy range 2.5$4.0 \mathrm{eV}$ results from the superposition of different bands associated with these transitions. Since the $\sigma(h v)$ spectrum character of $\mathrm{Cu}-\mathrm{Cr}$ solid solutions remains almost unchanged in the mentioned range, the structure of bands shifted from the Fermi level by $2.5-4.0 \mathrm{eV}$ in photon energy remains the same as for the pure $\mathrm{Cu}$. At last, the absorption spectrum character in the photon energy range 4.0-5.0 eV where the main absorption band of pure copper connected with transitions from $L_{3} d$-states to free levels of $L_{1}^{\prime}$ (see Fig. 4) does not change essentially in the alloys. Thus, the structure of $s, p, d$-bands shifted up to $5 \mathrm{eV}$ from the Fermi level is the same as in pure copper.

Thus, the study of optical properties of $\mathrm{Cu}-\mathrm{Cr}$ alloys with low $\mathrm{Cr}$ content (where it is well soluble in $\mathrm{Cu}$ ) show that the $s, p, d$-bands of copper remote at least $5 \mathrm{eV}$ from the Fermi level remain unchanged in their structure and energy spectral position. An impurity band is formed due to $\mathrm{Cr}$ situated under the Fermi level. Supposing that the new absorption band in the $\sigma(h v)$ optical spectra of $\mathrm{Cu}-$ $\mathrm{Cr}$ alloys in the photon energy range $0.8-1.6 \mathrm{eV}$ is related to electron transitions from the impurity $d$-underband to free electron states near the Fermi level, the position of impurity band center with respect to the Fermi level, $E_{d}-E_{F}$, and its half-width can be found basing on the experimental data.

The above facts indicate that $\mathrm{Cu} d$-bands can be smoothed out without any essential shift along the energy scale due to $\mathrm{Cu}$ and $\mathrm{Cr} d$-states hybridizing occurring when $\mathrm{Cr}$ concentration in the alloy increases. Moreover, an impurity band is formed situated under Fermi

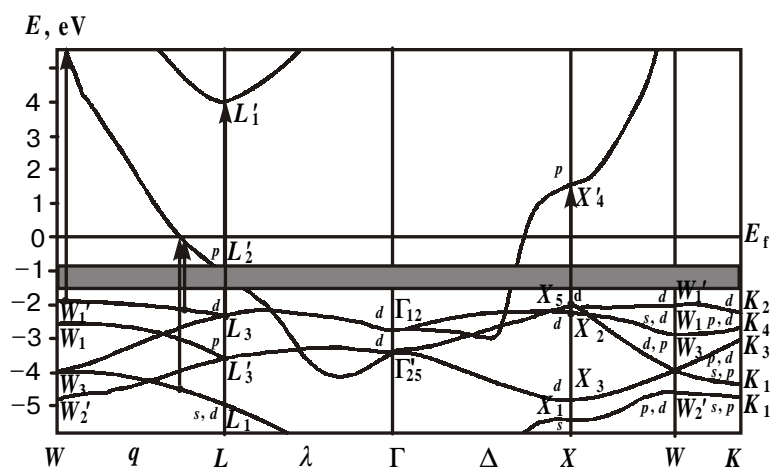

Fig. 4. Energy bands for $\mathrm{Cu}-\mathrm{Cr}$ alloys. Region of possible dipole transitions of electron shown by arrows. The impurity band of $\mathrm{Cu}$ and $\mathrm{Cr}$ solution is shadowed. 


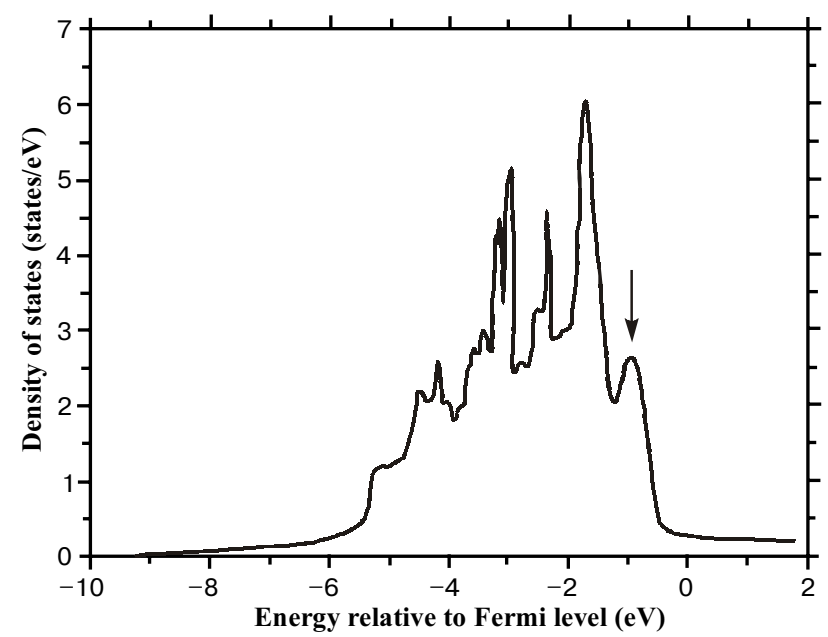

Fig. 5. Calculated state densities $\mathrm{N}(\mathrm{E})$ for $\mathrm{Cu}-\mathrm{Cr}$ alloy with $\mathrm{Cr}$ content 5 at. $\%$. The portion formed by impurity states, pointed by arrow.

level $E_{F}$ with $E(h v)$ increasing slightly with Cr concentration in the solution. If $\mathrm{Cr}$ would be well soluble in $\mathrm{Cu}$, a single band of the alloy should arise at high $\mathrm{Cr}$ concentration in the alloy, similar to the case of $\mathrm{Cu}-\mathrm{Ni}[3,9]$. However, according to our data, the maximum Cr solubility in $\mathrm{Cu}$ is not high (although being substantially higher than it was believed before) and it exceeds slightly 5 at. $\%$.

The state density $N(E)$ within the impurity band can be calculated basing on experimental data [8], processing from models of that band. On Fig. 5, the state density curves for the impurity band of $\mathrm{Cu}-\mathrm{Cr}$ solid solutions with 5 at. $\% \mathrm{Cr}$ is presented. Roughly speaking, the state density $N(E)$ for each mentioned solid solution is equal to the sum of state density within limits of the impurity band and that for pure copper.

\section{Conclusions}

It follows from the studies that the energy bands of alloys are similar to $\mathrm{Cu}$ at low $\mathrm{Cr}$ concentration when it is soluble well in $\mathrm{Cu}$ and $\mathrm{Cr}$ forms the impurity band situated nearly in the middle between the $\mathrm{Cu} d$-band top and the Fermi level $E_{F}$. Another variant is also possible which explains the nature of the low-intensity absorption band of the alloys in the range 1.6-1.7 eV. If it is assumed that incomplete solubility takes place even at small $\mathrm{Cr}$ amounts in copper, so that $\mathrm{Cr}$ clusters are formed, then the absorption band similar to $\mathrm{Cr}$ one is formed due the absorption by the clusters. The second $\mathrm{Cr}$ absorption peak at $1.95 \mathrm{eV}$ in the spectra may not appear because it is in the range of absorption minimum of pure copper. With increasing $\mathrm{Cr}$ concentration, it is possible that the size of clusters and their number increase only insignificantly, because $\mathrm{Cr}$ solubility in copper is increased. As $\mathrm{Cr}$ content increases, the structure of $\mathrm{Cu} d$-bands becomes slightly smoothed out without any essential shift along the energy scale. With increasing $\mathrm{Cr}$ concentration, the impurity band is widened and at high $\mathrm{Cr}$ concentrations, a single band of alloy can be formed at last. This cannot be realized to the full measure in the alloys under study, because the $\mathrm{Cr}$ solubility in $\mathrm{Cu}$ is limited, as is shown by the results of optical properties study on the alloy containing 30 at. $\%$ $\mathrm{Cr}$. It follows from the data presented that the electron spectrum of $\mathrm{Cu}-\mathrm{Cr}$ alloys is rather complicated. At low $\mathrm{Cr}$ concentrations (where it is well soluble in $\mathrm{Cu}$ ), the energy bands of the alloys are similar to those of copper while the Cr impurity forms an additional band situated between the top of $\mathrm{Cu} d$-band and Fermi level. The appearing of the impurity band in $\mathrm{Cu}-\mathrm{Cr}$ alloys is indisputable and it results in change of other physical properties of the alloys. At high $\mathrm{Cr}$ concentrations, clusters of this metal are formed, and the experimental spectra of the alloys are resulted from the superposition of spectrum of $\mathrm{Cu}-\mathrm{Cr}$ solution containing not less 5 at. $\% \mathrm{Cr}$ and that of pure $\mathrm{Cr}$.

The determination of the limiting $\mathrm{Cr}$ solubility in $\mathrm{Cu}$ is the most important result of $\mathrm{Cu}-\mathrm{Cr}$ alloy optical properties study; it exceeds slightly 5 at. \%. The optical method turned out to be extremely sensitive in determining the limiting $\mathrm{Cr}$ solubility in $\mathrm{Cu}$ as well as that of $\mathrm{Co}$ and $\mathrm{Fe}$ [10].

By studying the optical properties, it is found that at impurity concentrations $C<10$ at. \%, optical characteristics, such as refraction and absorption indices, dielectric constant , optical conductivity and the reflection coefficient under the normal incidence $R=\left((n-1)^{2}+\mathrm{a}^{2}\right) /$ $\left.(n+1)^{2}+\mathfrak{x}^{2}\right)$, depend non-linearly on the impurity concentration. This is due to a complicated transformation of the copper electron spectrum in the presence of $\mathrm{Fe}$, $\mathrm{Co}$, or $\mathrm{Cr}$ additives. At high impurity concentrations $(C>10$ at. \%), the alloys contain two phases and are heterogeneous mixtures of the almost pure $\mathrm{Fe}, \mathrm{Co}$ or $\mathrm{Cr}$ and a copper-based solid solution containing about $95 \% \mathrm{Cu}$. Experimental dependences of the mentioned optical characteristics on the wavelength result from superposition of $\mathrm{Fe}, \mathrm{Co}$ or Cr spectra and that of the mentioned solid solution with according weight coefficients

\section{References}

1. H. Ehreneich, L. Schwartz, The electron Structure of alloys, Academic Press, NY, 1976.

2. C. Cantoni, D.K. Christen, E.D. Specht // Supercond. Sci. Technol., 17 p. 341 (2004)

3. I.I. Sasovskaya, M.M. Noskov // Solid State Physics, 14(4), p. 999 (1972)

4. V.S. Staschuk, A.E. Doroshenko, S.N. Tkachenko // Fiz. Metal. Metaloved., 62(4), p. 830 (1986).

5. D.P. Norton, D.K. Freenstra, G.W. Ownby // Appl. Phys. Lett., 79, p. 3077 (2001).

6. V.S. Staschuk, Ukr. Fiz. Jurnal, 43(3) p. 282 (1998).

7. V.S. Staschuk, Ukr. Fiz. Jurnal, 41(5) p. 554 (1996).

8. V.L. Moruzzi, J.F. Janak, A.R. Williams, Calculated Electronic Properties of Metal, Pergamon Press Inc., NY, 1985.

9. F.A. List, A. Goyal, G.W. Zehner // J. Mater. Res., 17, p. 2549 (2001).

10. L.V. Poperenko, V.S. Staschuk, V.V. Vovchenko // Functional Mater., 7(3), p. 482 (2000). 